\title{
Reflexões sobre a trajetória da Assistência Social nas políticas de atendimento às crianças e aos adolescentes em situação de violência doméstica
}

\author{
Reflections about Social Assistance trajectory \\ on policies to assist children and adolescents in \\ domestic violence situation
}

\author{
Renata Alves da Silva* \\ Amanda de Oliveira Alves ${ }^{*}$ \\ Nayla Cristiana Beraldo Gonçalves ${ }^{* \star *}$
}

Resumo: 0 presente trabalho expõe uma discussão reflexiva sobre a trajetória da Assistência Social no que se refere às políticas de atendimento destinadas às crianças e aos adolescentes em situação de violência doméstica no Brasil, a partir da promulgação do Estatuto da Criança e do Adolescente - ECA. Apresenta ainda um panorama histórico das interpretações e atenções construídas socialmente sobre a infância e adolescência, bem como os avanços e desafios existentes no cenário atual. Tem por finalidade socializar contribuições analíticas acerca da temática, principalmente no que diz respeito às estratégias de prevenção e enfrentamento às violações de direitos contra crianças e adolescentes. A metodologia utilizada compreende um estudo teórico-bibliográfico e uma pesquisa documental de leis, portarias e normativas nacionais. As análises feitas apontam para a necessidade de permanentes esforços em prol da defesa e garantia dos direitos preconizados por este marco regulatório diante da ofensiva neoliberal.

Palavras-chave: Estatuto da Criança e do Adolescente. Violência doméstica. Política de Assistência Social.

Abstract: This study exposes a reflective discussion about Social Assistance trajectory regarding policies aimed at children and adolescents victims of domestic violence in Brazil, from the promulgation of the Child and Adolescent

\footnotetext{
${ }^{*}$ Mestre em História pela Universidade Federal do Espírito Santo (UFES). Bacharel em História pela Faculdade de Filosofia, Ciências e Letras de Alegre (FAFIA). Professora de História do Instituto Federal do Espírito Santo (IFES) do município de Alegre-ES. Brasil. E-mail: r.alegre@hotmail.com.

${ }^{* *}$ Especialista em Política de Assistência Social e Gestão do SUAS pela Faculdade Pitágoras de Belo Horizonte. Bacharel em Serviço Social pela Universidade Federal do Espírito Santo (UFES). Assistente Social do Centro de Referência Especializado de Assistência Social (CREAS) do município de Patos de Minas-MG. Brasil. E-mail: email.amandaalves@gmail.com.

*** Especialista em Políticas Públicas, Gestão e Serviços Sociais pela Universidade Cândido Mendes (UCAM). Bacharel em Serviço Social pela Universidade Federal de Ouro Preto (UFOP). Assistente Social do Centro de Referência Especializado de Assistência Social (CREAS) do município de Patos de Minas-MG. Brasil. E-mail: naylacristi@hotamail.com.
} 
Statute - ECA. It also presents a historical overview of the interpretations and attentions socially constructed on childhood and adolescence, as well as the advances and challenges in the current scenario. It aims to share analytical contributions on the theme, especially strategies for preventing and tackling rights violations. The methodology comprises a theoretical-bibliographic study and a research of laws, ordinances and national regulations. The analysis points to the need for permanent efforts to defend and guarantee the rights advocated by this regulatory framework in the face of neoliberal offensive.

Keywords: Child and Adolescent Statute. Domestic Violence. Social Assistance Policy.

Recebido em: 30/07/2020. Aceito em: 09/11/2020

\section{Introdução}

A conjuntura contemporânea tem demonstrado que as questões que perpassam o universo da infância e da adolescência permanecem sendo problematizadas. É incontestável a notoriedade de debates nos âmbitos sociais, políticos e científicos sobre a adoção de estratégias que viabilizem a garantia e a concretização dos direitos humanos da população infantojuvenil estabelecidos pelo Estatuto da Criança e do Adolescente (ECA). Isso significa dizer que a socialização e o reconhecimento das crianças e dos adolescentes como cidadãos em desenvolvimento possibilitam serem vistos como protagonistas da história presente.

Com o advento da redemocratização no Brasil na década de 1980, a situação da infância e adolescência ganhou novos olhares e marcos. Isto porque não foi apenas a abertura política que esteve em destaque nesse cenário, mas também a emergência de diversos movimentos sociais em prol da afirmação dos direitos humanos dos cidadãos, incluindo das crianças e dos adolescentes. As lutas desses movimentos repercutiram em novas legislações, práticas e instituições que deram visibilidade às questões até então, pouco reconhecidas, sendo o ECA a conquista com maior expressividade.

O ECA, portanto, constitui-se como um novo paradigma de proteção da infância e adolescência no Brasil, ao romper com a perspectiva da "Situação Irregular" presente no Código de Menores de 1979, de modo que contribui para a garantia de direitos e de políticas de atendimento voltadas exclusivamente para as crianças e adolescentes, associadas à corresponsabilidade da tríade Família, Estado e Sociedade. Com isso, a prevenção e o enfrentamento da ameaça ou violação dos direitos da criança e do adolescente configuram-se como dever de todos, conforme preconiza o Estatuto, no sentido de garantir que esses sujeitos não sejam objetos de violência, negligência, crueldade ou opressão.

As problematizações teóricas aqui apresentadas compreendem a violência como um fenômeno multidimensional e sócio-histórico que integra os complexos sociais, e por isso não pode ser interpretado de forma isolada, apenas na esfera individual-subjetiva, pois além de provocar efeitos diretos para o sujeito social que vivenciou uma situação real de violência, ocasiona intensos impactos socioculturais, políticos e econômicos. 
Alinhada a esta compreensão, Minayo (2001) define a violência contra criança e adolescente como o ato ou a omissão praticados por pessoas próximas como pais, parentes e até mesmo por instituições, que podem provocar danos e agravos físico, sexual, psicológico e emocional.

Apesar da existência de diversas normas protetivas para estas violações, as ocorrências ainda preocupam pelos números crescentes. Segundo dados do Relatório da Ouvidoria Nacional de Direitos Humanos de 2019, obtidos pelo canal "Disque 100", 55\% do total das denúncias foram de violações contra crianças e adolescentes, ou seja, o grupo vulnerável de maior registro de denúncias. As principais violações sofridas por esse grupo são, em escala decrescente, negligência, violência psicológica, física, sexual, institucional, e exploração do trabalho. Salienta-se que 52\% das violações ocorreram na casa da vítima, ao passo que $20 \%$ foram praticadas na casa do suspeito.

Conforme o Relatório, a maioria das violações é praticada por pessoas próximas ao convívio familiar (mãe, pai ou padrasto, tio, tia), o que condiz com a informação anterior da localidade das ocorrências das violações: casa da vítima ou do suspeito. Quanto à vítima, $55 \%$ são do sexo feminino, enquanto $45 \%$ são do sexo masculino. A vítima criança ou adolescente objeto da denúncia é predominantemente branca (42\%) ou parda (46\%), o que revela a inexpressividade do número de ocorrência envolvendo crianças e adolescentes de cor negra (11\%). Sobre as naturezas, a negligência é a violação de maior ocorrência, representando $38 \%$ dos registros. A violência sexual, abuso ou exploração sexual, consiste na quarta violação mais incidente com $11 \%$ dos casos, o que corresponde a 17 mil ocorrências. Em 2019 foram 86,8 mil denúncias de violações envolvendo crianças e adolescentes, o que figura um aumento de 14\% em relação a 2018 (BRASIL, 2019).

Diante das questões elucidadas, importa destacar a conceituação da violência que mais atinge este grupo. Por violência doméstica, compreendem-se as manifestações de violências ocorridas no espaço do lar ou, ainda que não localizadas neste espaço geográfico, são perpetradas por integrantes da família. Por este motivo, também é utilizada na literatura como sinônimo de violência intrafamiliar. Posto isto, a violência doméstica configura-se como uma das maiores causas de mortes e agravos contra crianças e adolescentes, sendo, portanto, uma das práticas que mais aflige este público de forma fatal e/ou severa (MINAYO, 2013).

A autora também salienta que as expressões de violência doméstica mais comuns no Brasil ocorrem contra crianças e adolescentes, mulheres e idosos, o que evidencia relações de gênero machistas e patriarcais e vários constructos culturais que fundamentam violências entre esses pares: pais/filhos e adultos/crianças (posição da autoridade); homens/mulheres (lógica da posse); adultos/idosos (lógica do descarte). Portanto, simboliza exercícios de poder e reprodução social da violência.

Dito de outro modo, a violência doméstica ou intrafamiliar se manifesta em usos, costumes, atitudes, negligências e atos que consolidam uma cultura de violência. São crenças que admitem e situam o homem como provedor e chefe da família, e portanto, aquele que detém o domínio e a posse do corpo da mulher. As crianças e os jovens para serem educados, necessitam ser castigados e punidos. E os idosos por não estarem mais inseridos na divisão social do trabalho, não produzirem bens e frequentemente demandarem cuidados, são considerados inúteis e descartáveis. Logo, qualquer trabalho de prevenção e enfrentamento a este tipo de violência, exige a desconstrução das crenças e mitos que promovem o poder machista, discriminam e contribuem para a reprodução do ciclo da violência entre os membros das famílias e suas gerações (MINAYO, 2013).

No que diz respeito à violência doméstica contra crianças e adolescentes, este artigo optou por incluir as ações das seguintes naturezas: física, psicológica, sexual, negligência e abandono, por serem as ocorrências mais comuns, todavia é sabido que outras violências ocorrem no ambiente 
doméstico como, por exemplo, o trabalho infantil e a violência patrimonial. Independente da forma como ela ocorre, fato é que as marcas da violência contra as crianças e os adolescentes impactam a saúde, a sociabilidade, a formação biopsicossocial e muitas vezes trazem consequências desastrosas ao longo de toda a vida destes sujeitos.

O ECA ao estabelecer políticas públicas de atendimento, permitiu que novos mecanismos de atenção e enfrentamento das violências sofridas pela população infantojuvenil se tornassem reais e com um papel de destaque. Nesse sentido, é inegável que pela natureza de algumas políticas sociais o processo de implementação de serviços, programas, projetos e benefícios para atender as crianças e adolescentes em situação de violência, assim como as suas famílias, tenham adquirido maior proeminência, como é o caso da Assistência Social, por meio do Sistema Único de Assistência Social (SUAS).

Assim, a política de Assistência Social consolidou-se no mesmo período das mudanças da política de proteção às crianças e adolescentes, de modo que se inter-relacionam tanto na trajetória histórica quanto nos objetivos para com este segmento etário. Na medida em que a Assistência Social rompe com práticas assistencialistas e estabelece um novo patamar de política pública, serviços universalizantes passam a ser ofertados para a promoção e garantia da acolhida, do convívio, do rendimento e da equidade para indivíduos e famílias em situação de risco e vulnerabilidade, o que inclui crianças e adolescentes com direitos violados.

Partindo da premissa de que um dos objetivos da Assistência Social é a proteção da infância e da adolescência (LOAS, 1993) compreende-se neste texto a necessidade de se apresentar e analisar quais foram as suas ações ao longo dos últimos 30 anos no que diz respeito à prevenção e o enfrentamento da violência doméstica às crianças e adolescentes.

Dessa forma, o presente artigo tem como objetivo norteador a exposição de um balanço analítico-reflexivo sobre as políticas de atendimento de prevenção e enfrentamento à violência doméstica desenvolvidas no âmbito da Assistência Social para crianças e adolescentes. Para tal análise, apresenta um panorama histórico das interpretações e atenções construídas socialmente sobre a infância e a adolescência, observando os possíveis avanços e desafios presentes nos 30 (trinta) anos de vigência do ECA.

A metodologia adotada concentrou-se na realização de um estudo teórico-bibliográfico de textos, livros e artigos acadêmicos da literatura nacional e internacional que discutem sobre as violências no universo da infância e da adolescência. Inclui ainda uma pesquisa documental de leis, portarias e normativas sobre as políticas de atendimento desenvolvidas na área da Assistência Social destinadas às crianças e adolescentes vítimas de violência doméstica.

Com o intuito de apresentar discussões relevantes, este trabalho encontra-se organizado em três seções. A primeira aborda sobre as relações existentes entre infância, adolescência e violência ao resgatar a trajetória histórica que perpassa tais relações. Na segunda são apontados as evoluções e os aspectos que caracterizam as políticas de atendimento no interior da Assistência Social voltadas para as crianças e adolescentes em situação de violência doméstica a partir do advento do ECA. E por fim, mas não menos importante, a terceira expõe um panorama dos avanços e desafios destas políticas nos 30 (trinta) anos de existência do Estatuto supramencionado.

\section{Violência, Infância e Adolescência: notas de uma antiga e perversa relação}

Os processos relacionais que envolvem a vida em sociedade são marcados por aspectos multifatoriais que se inter-relacionam, na medida em que são produzidos e reproduzidos os 
condicionantes objetivos e subjetivos dos sujeitos. Desse modo, as diversas formas de violência se manifestam nas condições sociais da existência humana com (re)configurações e contornos que se agravam permanentemente, e expressam a necessidade de adoção de estratégias de enfrentamento.

A compreensão da violência como um fenômeno sócio-histórico é desafiadora, e por isso diversos teóricos e estudiosos se debruçam sobre a sua complexidade. Há uma gama de interpretações e perspectivas conceituais sobre o tema, sendo que neste artigo a definição apresentada sustenta-se nas ideias de Chauí (1998), ao definir esta categoria como:

1) tudo o que age usando a força para ir contra a natureza de algum ser (é desnaturar); 2) todo ato de força contra a espontaneidade, a vontade e a liberdade de alguém (é coagir, constranger, torturar, brutalizar); 3) todo ato de violação da natureza de alguém ou de alguma coisa valorizada positivamente por uma sociedade (é violar); 4) todo ato de transgressão contra aquelas coisas e ações que alguém ou uma sociedade define como justas e como um direito; 5) consequentemente, violência é um ato de brutalidade, sevícia e abuso físico e/ou psíquico contra alguém e caracteriza relações intersubjetivas e sociais definidas pela opressão, intimidação, pelo medo e pelo terror (CHAUí, 1998, p. 03).

As considerações apresentadas por Chauí (1998) indicam que nas relações regidas pela violência o ser humano tem seus direitos violados, o que ocasiona a perda provisória e/ou permanente da sua liberdade e razão, ao ser submetido a práticas de tortura, constrangimento, crueldade e sofrimento.

Minayo (2003) ressalta que a violência enquanto uma categoria ontológica que se expressa nos processos históricos, precisa ser entendida na totalidade social, isto é, não pode ser deslocada da sociedade que a produz e reproduz, uma vez que recebe influências políticas, econômicas e culturais. Acrescenta ainda, que as práticas de violências estão diretamente relacionadas com situações que envolvem conflitos pelo estabelecimento do domínio e do poder, sendo estas muitas das vezes naturalizadas socialmente.

Vale ressaltar que as situações de violência são expressões da questão social ${ }^{1}$ nos marcos da sociabilidade capitalista, uma vez que se apresentam nas tramas das relações sociais e disseminam desigualdades estruturais e conjunturais geradas pelo capitalismo, principalmente no cenário contemporâneo. Em conformidade com esta argumentação Iamamoto (2008), salienta que

[...] o predomínio do capital fetiche conduz à banalização do humano, à descartabilidade e indiferença perante o outro, o que se encontra na raiz das novas configurações da questão social na era das finanças (IAMAMOTO, 2008, p. 125).

Sendo assim, o entendimento da violência em uma perspectiva crítica implica necessariamente a superação de concepções conservadoras, limitantes, e desconexas dos processos históricos e da dinâmica societária. O percurso analítico, portanto, precisa estar alinhado a (des) naturalização desse fenômeno social.

Segundo a Organização Mundial de Saúde (OMS), a violência é classificada em três categorias: Autoprovocada (violência praticada contra si mesmo), Interpessoal (cometidas por

\footnotetext{
${ }^{1}$ A questão social diz respeito ao conjunto das expressões das desigualdades sociais engendradas na sociedade capitalista madura [...] expressa, portanto disparidades econômicas, políticas e culturais das classes sociais, mediatizadas por relações de gênero, características étnico-raciais e formações regionais, colocando em causa as relações entre amplos segmentos da sociedade civil e ou poder estatal (IAMAMOTO, 2001, p. 16-17).
} 
indivíduos ou grupos) e Coletiva (praticada por estados, organizações, grupos armados, milícias e grupos terroristas). A concretização destas categorias está diretamente relacionada ao tipo de natureza da violência as quais podem ser: física, sexual, psicológica e negligência/abandono (KRUG et al., 2002).

\section{Quadro 1 - Tipos e natureza das principais violências que atingem crianças e adolescentes}

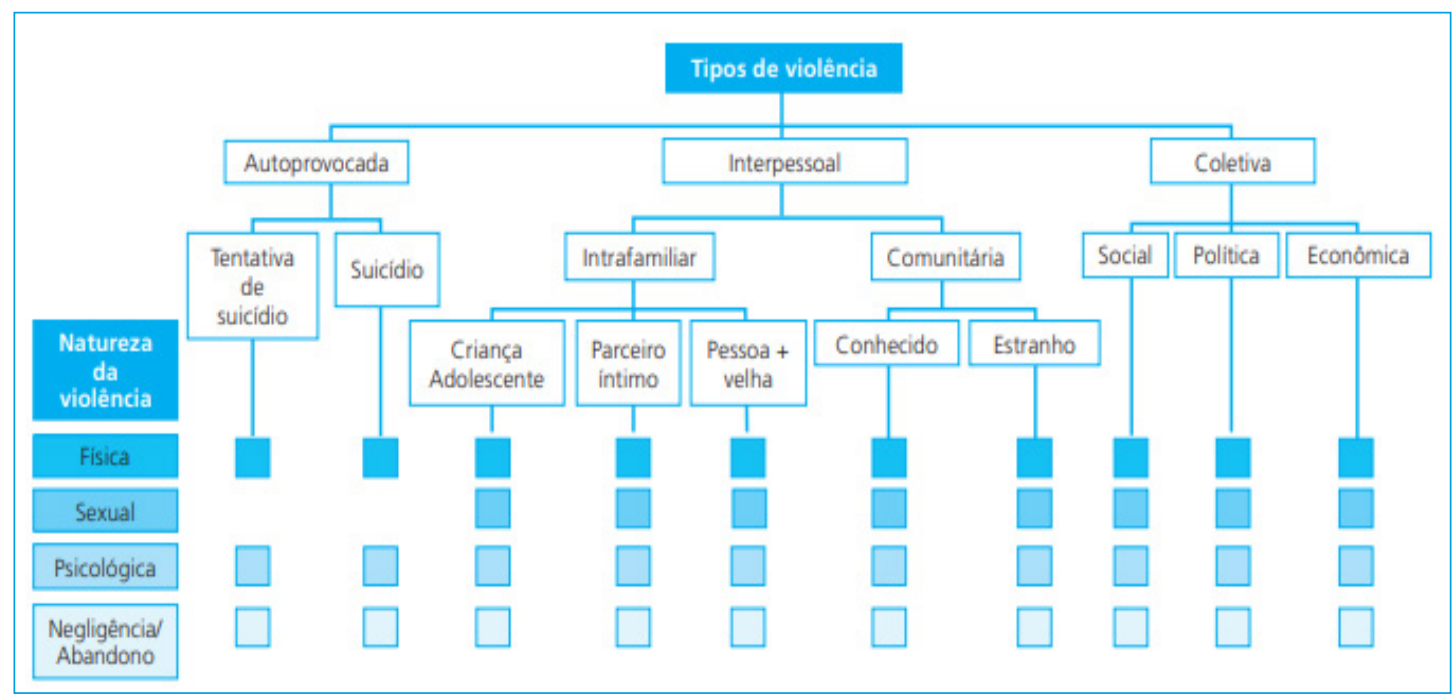

Fonte: (KRUG et al., 2002).

O quadro evidencia os aspectos e as relações entre os diferentes tipos e natureza da violência, de modo que entende-se que a violência doméstica contra as crianças e adolescentes, está classificada como violência interpessoal e intrafamiliar. Ressalta-se que o conhecimento das diferentes formas de manifestação da violência que mais afetam este público é fundamental para a ampliação do cuidado e da proteção social.

As discussões referentes à violência são amplas e desafiadoras nos marcos atuais, considerando a intensificação e o agravamento de suas manifestações na vida em sociedade. Neste trabalho, propõe-se uma aproximação desta categoria a partir do marco relacional com o universo da infância e adolescência. Posto isto, faz-se necessário o entendimento de que a violência contra a criança e o adolescente

[...] é todo ato ou omissão cometidos por pais, parentes, outras pessoas e instituições, capazes de causar dano físico, sexual e/ou psicológico à vítima. Implica, de um lado, numa transgressão no poder/dever de proteção do adulto e da sociedade em geral; e de outro, numa coisificação da infância. Isto é, numa negação do direito que crianças e adolescentes têm de serem tratados como sujeitos e pessoas em condições especiais de crescimento e desenvolvimento (MINAYO, 2001, p. 92).

As diversas expressões da violência que afetam a população infantojuvenil estão diretamente ligadas aos pressupostos sócio-históricos, por isso a necessidade de reconhecê-las nas demandas coletivas e de classes que integram a sociabilidade humana. Nessa ótica de entendimento, Faleiros (1998) destaca que o processo de construção da infância se gesta nos sistemas cultural, imaginário e simbólico enquanto produto das relações sociais em determinados momentos da história. 
A materialização das violências contra crianças e adolescentes envolve reiteradamente relações de poder, pois fomenta práticas que se apropriam de dimensões que os compõe como pessoas, por exemplo, o discernimento, a liberdade de escolha, os processos decisórios. Tais relações de poder se expressam por meio de repressão, martírios, autoritarismo e podem estar presentes tanto nos contextos familiares quanto institucionais (FALEIROS, 1998).

As análises feitas por Assis (1994 apud Minayo, 2001) indicam que a trajetória histórica do gênero humano é marcada por acontecimentos de violência contra a população infantil desde os tempos primitivos com inúmeras manifestações e influências culturais. Cita como exemplo emblemático, a aceitação nas sociedades antigas de práticas como infanticídio, em que era facultado aos pais o direito de acolher ou renegar o filho recém-nascido.

A história apresenta indicativos de que durante muito tempo a criança era vista como um "adulto precoce", no qual não era considerado o seu processo de desenvolvimento. As demandas infantis eram tratadas com práticas repressivas, autoritárias e coercitivas. Ariès (1981) afirma que na Idade Média não existia o sentimento de infância e as crianças viviam uma antecipação das responsabilidades da vida adulta.

O referido autor também salienta que a adolescência enquanto uma fase específica só foi reconhecida no final do século XIX e início do século XX, ao considerá-la como uma preparação para a vida adulta. Isso significa dizer que a compreensão da infância e da adolescência como etapas distintas e com características próprias são provenientes da modernidade (ARIÈS, 1981).

Em momentos históricos posteriores o significado da infância e adolescência permaneceu sendo desvalorizado com a predominância da visão adultocêntrica e patriarcal. Estas fases da vida não eram compreendidas pelas suas questões específicas. Assim, as crianças e os adolescentes estavam desprovidos socialmente de proteção e de direitos.

Conforme DelPriore (2004), a noção de infância construída historicamente no Brasil está atrelada às dimensões constitutivas do país, o que inclui o processo de colonização, escravidão, exploração de mão de obra indígena e os outros processos sócio-históricos que marcaram as atenções assistencialistas e focalizadas para este grupo etário.

Rizzini (1997) ao considerar a história das políticas sociais voltadas para a criança e o adolescente no Brasil enfatiza que as ações estatais nessa direção se concretizaram a partir do século XX. As primeiras medidas adotadas destinavam-se aos meninos pobres, excluindo as meninas e os escravos.

A preocupação estatal com a infância estava relacionada ao interesse de transformar o Brasil em uma nação mais "dócil" sob a ótica de entendimento que essa etapa da vida era decisiva para que o indivíduo seguisse o caminho do bem. Nesse sentido, Melim (2012) ressalta que as principais iniciativas tinham como foco central a infância empobrecida, com vinculações diretas ao mundo do trabalho, uma vez que acreditavam que o "menor" pobre só poderia ser recuperado por meio do trabalho.

Essas práticas foram perpetuadas durante longos anos da República e em 1927 instituiu-se a primeira legislação brasileira direcionada para a infância, o chamado Código de Mello Mattos. As diretrizes estabelecidas reforçavam as práticas anteriores e enfatizavam a internação de "menores" empobrecidos. Apesar da significância dessa Lei, foi apenas nos anos de 1940 que ocorreu a implementação de uma política de atendimento mais expressiva, com a criação de órgãos federais responsáveis pela gestão e oferta de ações para a população infantojuvenil, com destaque para o Serviço de Atendimento ao Menor (SAM) (RIZZINI, 1997). 
Em um processo de substituição ao SAM em 1964 foram criadas a Fundação Nacional de Bem-Estar do Menor (FUNABEM) e as Fundações Estaduais de Bem-Estar do Menor (FEBEM's). A política de atendimento aos "menores" pobres adquiriam novas instituições, porém não alteravam o formato predominante de controle repressivo desta parcela da população (MELIM, 2012).

É importante frisar que mundialmente o século XX foi marcado por notáveis mudanças nas visões interpretativas dos direitos da criança e do adolescente. Em 1924, foi elaborada a Declaração de Genebra, aprovada pela Liga das Nações e consagrada como "Carta da Liga sobre Crianças". Já no ano de 1959, a Organização das Nações Unidas (ONU) conseguiu implementar avanços significativos ao aprovar a Declaração dos Direitos da Criança. Em continuidade às ações, em 1979 a ONU estabeleceu como o Ano da Criança e em 1990, a Convenção sobre os Direitos da Criança entrou em vigor, o que proporcionou avanços significativos na defesa e garantia dos direitos infantojuvenis (DOLINGER, 2003).

No final da década de 1980, a sociedade brasileira vivenciara uma efervescência política com a intensificação de bandeiras de lutas pela garantia de direitos civis, políticos e sociais. Esse processo de transição político-democrática ficou conhecido como redemocratização. As reivindicações em prol da criança e do adolescente concentravam-se na defesa de direitos e de alterações no Código de Menores de 1979, pois já estava defasado para a época.

O Código de Menores de 1979 constituía-se uma extensão das concepções presentes no Código Mello Mattos e devido o contexto de ditadura militar não apresentava alinhamento com as perspectivas internacionais. Esta legislação (1979) estabelecia que ações estatais de assistência, vigilância e proteção deveriam ser destinadas aos menores pobres considerados "delinquentes", "abandonados", ou seja, para aqueles que se encontravam em situação irregular e ocasionavam transtornos para a sociedade brasileira (MELIM, 2012).

Os debates político-democráticos e as mobilizações sociais no país confluíram para a promulgação em 1988 da Constituição Federal (CF), que trouxe um arsenal inovador de garantias e de direitos sociais, civis e políticos para todos os cidadãos brasileiros. Conhecida como "Constituição Cidadã", possibilitou um novo olhar sobre a infância e a adolescência no país, ao considerar as crianças e adolescentes como sujeitos de direitos com prioridade absoluta. $\mathrm{O}$ seu Artigo 227 estabelece que:

É dever da família, da sociedade e do Estado assegurar à criança, ao adolescente e ao jovem, com absoluta prioridade, o direito à vida, à saúde, à alimentação, à educação, ao lazer, à profissionalização, à cultura, à dignidade, ao respeito, à liberdade e à convivência familiar e comunitária, além de colocá-los a salvo de toda forma de negligência, discriminação, exploração, violência, crueldade e opressão (BRASIL, 1988).

Diante das concepções consolidadas com a Carta Magna, a proteção das crianças e dos adolescentes passou ter espaço significativo na agenda pública e em todos os segmentos da sociedade, considerando a necessidade de garantir o desenvolvimento peculiar desses indivíduos. É nesse contexto que foi aprovado em 1990 o Estatuto da Criança e do Adolescente (ECA - Lei no 8.069, de 13 de julho de 1990).

A promulgação do ECA revogou o antigo Código de Menores e concretizou a Doutrina da Proteção Integral ao mudar a concepção de criança e adolescente entendendo-os como sujeito de direitos individuais e coletivos. 
Cabe ressaltar que o ECA ao reconhecer a necessidade de proteção integral, demarca a importância de garantir que todas as crianças e adolescentes não sejam objetos de violência, conforme observa-se em seu artigo $5^{\circ}$.

Nenhuma criança ou adolescente será objeto de qualquer forma de negligência, discriminação, exploração, violência, crueldade e opressão, punido na forma da lei qualquer atentado, por ação ou omissão, aos seus direitos fundamentais (BRASIL, 1990).

Com o intuito de efetivar o cumprimento deste artigo, o documento instituiu alguns mecanismos de defesa como, a constituição dos Conselhos Tutelares; a definição das medidas protetivas; a previsão de políticas de atendimento; o estabelecimento de entidades de atendimento; o papel da Justiça; dentre outros.

Assim, considerando a relação entre infância e violência e as transformações no trato da questão no decorrer da história, sobretudo após a promulgação do ECA, a próxima seção irá abordar as políticas de atendimento da Assistência Social voltadas à prevenção e enfrentamento da violência contra crianças e adolescentes. Para viabilizar o percurso metodológico, abordaremos as ações nas áreas de violência doméstica em suas naturezas física, psicológica, sexual, negligência e abandono.

\section{O ECA e a Assistência Social na oferta das políticas de atendimento à criança e ao adolescente em situação de violência doméstica}

A partir do novo padrão político, jurídico e social instituído sobre a infância e a adolescência com o ECA, o legislador teve o cuidado em garantir a operacionalização dos direitos declarados (Direitos fundamentais - Capítulos I ao V), através das denominadas Políticas de Atendimento.

Art. 86. A política de atendimento dos direitos da criança e do adolescente far-se-á através de um conjunto articulado de ações governamentais e não-governamentais, da União, dos estados, do Distrito Federal e dos municípios (BRASIL, 1990).

As Políticas de Atendimento são entendidas como um conjunto de serviços, programas e ações básicas para a garantia dos direitos sociais e de cidadania das crianças e dos adolescentes. Tais políticas estão atreladas às diretrizes de universalização, compromisso normativo, participação social e à concepção destes indivíduos como sujeitos de direitos e objetos da proteção do Estado.

Compreendem as políticas de atendimento, ações de diversas políticas como as de Assistência Social, Saúde, Educação, Direitos Humanos, Cultura, Esporte, dentre outras correlatas que por sua vez deverão implementar serviços de atendimento, estabelecer parâmetros e legislações, assegurar mecanismos de representação democrática de modo a atender as necessidades primordiais das crianças e adolescentes e garantir o efetivo exercício dos direitos.

As políticas de atendimento não são estanques e estão num contínuo processo de aperfeiçoamento e embora sejam datadas aqui a partir de 1990, são fruto da história da infância e adolescência no país, no qual paulatinamente ampliou e consolidou o conceito de cidadania.

o conceito basilar das políticas de atendimento elucida o entendimento que a criança e o adolescente, bem como suas respectivas famílias, devem estar amparados por políticas públicas de proteção, promoção e direitos (RIZZINI; NAIFF; BAPTISTA, 2006). 
Atualmente tais políticas são definidas em sete linhas de ação segundo o ECA (1990), a saber:

Art. 87. São linhas de ação da política de atendimento:

I - políticas sociais básicas;

II - políticas e programas de assistência social, em caráter supletivo, para aqueles que deles necessitem;

(Revogado)

II - serviços, programas, projetos e benefícios de assistência social de garantia de proteção social e de prevenção e redução de violações de direitos, seus agravamentos ou reincidências; (Redação dada pela Lei n⒔257, de 2016)

III - serviços especiais de prevenção e atendimento médico e psicossocial às vítimas de negligência, maus-tratos, exploração, abuso, crueldade e opressão;

IV - serviço de identificação e localização de pais, responsável, crianças e adolescentes desaparecidos;

V - proteção jurídico social por entidades de defesa dos direitos da criança e do adolescente.

VI - políticas e programas destinados a prevenir ou abreviar o período de afastamento do convívio familiar e a garantir o efetivo exercício do direito à convivência familiar de crianças e adolescentes; (Incluído pela Lei no 12.010, de 2009) Vigência

VII - campanhas de estímulo ao acolhimento sob forma de guarda de crianças e adolescentes afastados do convívio familiar e à adoção, especificamente inter-racial, de crianças maiores ou de adolescentes, com necessidades específicas de saúde ou com deficiências e de grupos de irmãos. (Incluído pela Lei no 12.010, de 2009) (BRASIL, 1990, grifo nosso).

Tendo como premissa os incisos II e III, pretende-se neste ensaio resgatar a trajetória histórica das políticas de atendimento destinadas à prevenção e promoção social dos direitos da criança e do adolescente em situação de violência. Para tal, será feito um recorte por meio da política pública de Assistência Social com ênfase na violência doméstica.

\section{A Assistência Social e as Políticas de Atendimento: um olhar sobre a violência doméstica às crianças e aos adolescentes}

A Constituição Federal (CF) de 1988 foi um importante e pioneiro marco legal por ter estabelecido nos artigos 203 e 204 a Assistência Social como política pública, um direito de todos e não contributiva, ou seja, é destinada a quem dela necessitar e assegurada pelo Estado. Em seus objetivos, traz um preceito no qual irá nortear todas as suas ações, incluindo as que envolvem às crianças e os adolescentes: o conceito de proteção social.

Segundo Jaccoud (2009, p. 58):

A proteção social pode ser definida como um conjunto de iniciativas públicas ou estatalmente reguladas para a provisão de serviços e benefícios sociais visando enfrentar situações de risco social ou privações sociais. [...] Seus objetivos são amplos e complexos, podendo organizar-se não apenas para a cobertura de riscos sociais, mas também para a equalização de oportunidades, $o$ 
enfrentamento das situações de destituição e pobreza, o combate às desigualdades sociais e a melhoria das condições sociais da população.

Dessa forma, o modelo de proteção social no Brasil sofre metamorfoses que a partir da promulgação da CF (1988) culminou no estabelecimento da Seguridade Social, o tripé: Assistência Social, Saúde e Previdência Social. A Assistência Social por sua vez irá ofertar o modelo de proteção social não contributivo, destinado a prevenir e enfrentar situações de risco e vulnerabilidade em decorrência dos ciclos de vida (infância, adolescência, juventude, velhice) das identidades (gênero, raça, etnia, orientação sexual), das violências (maus tratos, abandono, negligência, abuso e exploração sexual, tráfico de pessoas, trabalho infantil) e da desigualdade social (pobreza, desemprego, fome, condições habitacionais, situação de rua etc.).

Deste modo, a partir da sua constituição enquanto política pública, a Assistência Social passou a ter como um dos seus objetos de intervenção a proteção das crianças e adolescentes, especialmente no ambiente doméstico, haja vista os índices de violações ali ocorridos e as vulnerabilidades e riscos a que estão expostos nesse ambiente.

Com o intuito de regulamentar os artigos 203 e 204 da CF (1988), em 1993, foi criada a Lei Orgânica da Assistência Social (LOAS) no qual regulamenta, define e garante os direitos socioassistenciais. Esta Lei dispõe sobre o conjunto de benefícios, programas, serviços e projetos necessários ao cumprimento dos seus objetivos. Estabelece por diretrizes da Assistência Social a descentralização político-administrativa das ações; a participação da população e a primazia da responsabilidade do Estado na condução desta política em cada esfera de governo.

Destaque na LOAS, para a inter-relação entre a proteção social da infância e adolescência e a Assistência Social, de modo que em seus objetivos, consta sua proteção e amparo:

Art. 2ำ A assistência social tem por objetivos:

I - a proteção social, que visa à garantia da vida, à redução de danos e à prevenção da incidência de riscos, especialmente:

a) a proteção à família, à maternidade, à infância, à adolescência e à velhice;

b) o amparo às crianças e aos adolescentes carentes; [...] (BRASIL, 1993).

Em 1995, houve a elaboração da Política Nacional de Assistência Social (PNAS), no qual pela primeira vez expressava o público, os objetivos, as diretrizes e as prioridades desta política. Em 1998, a política foi reformulada, porém foi a versão de 2004 que expressou um grande avanço conceitual e político. O documento apresenta as bases da organização e gestão do Sistema Único de Assistência Social (SUAS) e fundamenta suas ações em três referências: a proteção social, a vigilância social e a defesa social e institucional.

Considerando os objetivos e o público destinatário da Assistência Social, depreende-se que o percurso das políticas de atendimento às crianças e aos adolescentes em situação de violência perpassa a trajetória da política de Assistência Social, visto que por ter em seu objetivo a proteção à família, à maternidade, à infância e à adolescência, é em seu interior que serão criados importantes serviços e programas destinados à prevenção e/ou enfrentamento da violência à criança e ao adolescente.

A partir da pesquisa bibliográfica efetuada verificou-se que durante a década de 1990, no âmbito da Assistência Social, as crianças e os adolescentes em situação de violência sexual ou doméstica eram atendidos por Organizações não Governamentais (ONGs) e por iniciativas isoladas 
nos municípios e estados. Nessa década os Conselhos Tutelares já haviam iniciado suas ações, em função do estabelecido no art.131 do ECA, todavia contavam com poucos recursos para aplicação das medidas protetivas. Restando-lhes o encaminhamento para orfanatos, fundações filantrópicas, serviços de atendimento à vítima em alguns hospitais e centros especializados de pediatria, quando existentes. Ressalta-se que apenas a partir dos anos 2000 que programas e ações foram institucionalizados pelo Governo Federal (BRASIL, 1990, 2002, 2017; MARTINS; JORGE, 2010).

Com relação à violência e exploração sexual de crianças e adolescentes somente após a instalação da Comissão Parlamentar de Inquérito (CPI) da Prostituição Infantil no Congresso Nacional em 1993, é que o assunto teve visibilidade em nível nacional. Além da apuração de irregularidades, houve uma intensa mobilização da sociedade que culminou o surgimento de fóruns, comitês, redes, etc., para a elaboração de uma política de atendimento às vítimas e enfrentamento da questão (NASCIMENTO; DESLANDES, 2016).

Como resultado deste debate, em 2000 foi elaborado o Plano Nacional de Enfrentamento da Violência Sexual Infanto juvenil. Em 2002 foi iniciado o Programa Sentinela - Programa de Combate ao Abuso e à Exploração Sexual de Crianças e Adolescentes, uma resposta governamental destinado ao atendimento especializado às crianças e adolescentes vítimas de abuso ou exploração sexual, bem como aos seus familiares, com o objetivo de reparação da violência vivida e superação da violação de direitos (NASCIMENTO; DESLANDES, 2016).

O Programa foi criado em dezembro de 2001, através da Portaria, $n^{\circ} 878 / 2001$, sob a responsabilidade do então Ministério da Previdência e Assistência Social (MPAS) (BRASIL, 2002). 0 Programa atuava por meio de um conjunto articulado de ações com a finalidade de criar condições que possibilitasse às crianças e aos adolescentes e suas famílias, o resgate e a garantia dos direitos, o acesso aos serviços das políticas sociais básicas.

O Programa Sentinela vigorou até 2005, quando suas atividades foram incorporadas durante um período, pelo Serviço de Enfrentamento à Violência, ao Abuso e à Exploração Sexual contra Crianças e Adolescentes ofertado pelos Centros de Referência Especializados de Assistência Social (CREAS). Com a Resolução do Conselho Nacional de Assistência Social (CNAS) nº 109, de 11/11/2009 - Tipificação Nacional de Serviços Socioassistenciais, o serviço foi integrado ao Serviço de Proteção e Atendimento Especializado a Famílias e Indivíduos (PAEFI), desenvolvido igualmente no CREAS e em vigor até o presente momento.

Assim, o Sentinela, teve sua transição de um "programa" para um "serviço continuado" a ser desenvolvido pelos CREAS, em função das modificações no âmbito da PNAS (2004), com a criação e consolidação do SUAS.

Com a implantação do SUAS, a oferta dos serviços, programas e projetos da Assistência Social foi organizada em proteção social básica, destinada a prevenir situações de risco, e proteção social especial (média complexidade e alta complexidade), para quando os direitos já foram violados e os vínculos familiares e/ou comunitários estão frágeis ou rompidos.

Os Centros de Referência de Assistência Social (CRAS) são as unidades públicas estatais de referência para a execução da proteção social básica e organização da rede local de serviços socioassistenciais. São responsáveis pela oferta do Serviço de Proteção e Atendimento Integral à Família (PAIF) e pelo Serviço de Convivência e Fortalecimento de Vínculos (SCFV) e está presente em mais de 5.000 municípios brasileiros (BRASIL, 2004; 2013). Neste sentido, o CRAS ao ofertar serviços, programas, projetos e benefícios de assistência social, constitui-se diretamente como uma política de atendimento prevista no Art. 87, inciso II (BRASIL, 1990), portanto, colaborando para a prevenção e redução de violações de direitos, seus agravamentos ou reincidências. 
Para a execução da proteção social especial de média complexidade, os CREAS são as unidades de referência. São destinados ao trabalho social com famílias e indivíduos em situação de violação de direitos em decorrência de: violência física; violência psicológica; negligência, maus tratos; violência sexual (abuso e/ou exploração sexual); afastamento do convívio familiar devido à aplicação de medida socioeducativa ou medida de proteção; tráfico de pessoas; situação de rua; abandono; situação de trabalho infantil; discriminação em decorrência da orientação sexual e/ ou raça/etnia; e descumprimento de condicionalidades do Programa Bolsa Família resultante de violação de direitos (BRASIL, 2004; BRASIL, 2009).

Dentre os diversos serviços e programas ofertados para atender tais demandas, destaque para o PAEFI, que conta com uma equipe multidisciplinar (assistente social, psicólogo, pedagogo, advogado), responsável por oferecer apoio, orientação e acompanhamento a famílias e indivíduos em situação de violação de direitos, sendo que o maior índice de atendimentos deste serviço relaciona-se às crianças e aos adolescentes (BRASIL, 2017).

Atualmente ele é o principal serviço da Assistência Social para a oferta de ações destinadas ao atendimento de crianças e adolescentes em situação de violência. Desse modo, configura-se como uma importante política de atendimento deste segmento etário conforme previsto no art.87 do ECA, em seu inciso III, por se apresentar como um serviço especializado de atendimento psicossocial às vítimas de negligência, maus-tratos, exploração, abuso e exploração sexual.

Em prosseguimento, as Instituições de Acolhimento (Abrigos e Casa-lar) são as unidades de referência para a execução da proteção social especial de alta complexidade. São destinadas ao abrigo provisório de crianças e adolescentes afastados do convívio familiar por meio de medida protetiva (ECA, art.101), aplicada por autoridade judicial, em função da impossibilidade temporária das famílias ou responsáveis em cumprirem sua função de cuidado e proteção, até que seja viabilizada a reintegração familiar, ou, na sua impossibilidade, o encaminhamento para uma família substituta (BRASIL, 2017).

Estas Unidades de Acolhimento são utilizadas diante de situações de grave risco à integridade física e/ou psíquica das crianças e adolescentes, portanto, via de regra, corresponde a uma política de atendimento voltada à situações extremas já ocorridas de violência, sobretudo abandono e negligência. Portanto, corresponde como o último recurso a ser acessado pela rede de proteção e simboliza a falha das políticas de prevenção. Destaque para a Lei nº 12.010 de 03 de agosto de 2009 (Lei Nacional de Adoção) e o Plano Nacional de Promoção, Proteção e Defesa dos Direitos de Crianças e Adolescentes à Convivência Familiar e Comunitária que dentre os seus objetivos trouxeram avanços ao romper com a cultura da institucionalização e no fortalecimento da proteção integral e na preservação dos vínculos familiares e/ou comunitários.

Assim, a partir do percurso apresentado, verifica-se que o Estado brasileiro tardou a concretização dos dispositivos presentes na LOAS, o que consequentemente fez com que a Assistência Social, como política pública, fosse deixada em segundo plano, ao considerarmos o tripé da Seguridade Social brasileira. Nesse sentido, a oferta das políticas de atendimento de caráter público voltadas para as crianças e adolescentes em situação de violência ocorreu somente em 2002 com o Programa Sentinela, facultando até esta data, aos estados, municípios e organizações da sociedade civil oferecerem de forma isolada serviços de prevenção e enfrentamento das violências, o que resultou muitas vezes em uma oferta precária ou descontinuada.

Todavia com a implantação do SUAS, vê-se um salto qualitativo, uma vez que praticamente todos os municípios brasileiros atualmente possuem meios de operacionalizar políticas de atendimento às crianças e adolescentes seja por meio dos CRAS ou CREAS. 
A próxima seção destina-se a continuidade das reflexões acima elencadas aprofundando os contrapontos entre as evoluções e os entraves das políticas de atendimento às vítimas de violência no âmbito da Assistência Social, à luz de uma perspectiva crítica-normativa.

\section{As políticas de atendimento nos trinta anos do ECA: um panorama sobre os avanços e desafios}

O processo de construção e defesa dos direitos da criança e do adolescente adquirem contornos distintos em cada país, apesar de fazerem parte de uma dimensão de totalidade. Diante dessa reflexão é preciso considerar que no Brasil houve avanços significativos tendo em vista as suas particularidades sócio-históricas.

As reformulações das formas interventivas do Estado a partir da CF e do ECA deixaram de ser verticais e centralizadoras e adquiriram perspectivas de garantias de cidadania tanto do ponto de vista individual (vida, liberdade e dignidade) quanto coletivo (econômico, social e cultural). O referido Estatuto oportunizou mudanças legais na formulação de políticas sociais voltadas para a infância e a adolescência por meio da estruturação de organismos destinados ao atendimento deste público.

O ECA ao estabelecer as políticas de atendimento à infância e adolescência firmadas na descentralização político-administrativa e na participação da sociedade através das organizações representativas, proporcionou mudanças expressivas na gestão (relações entre União, Estados e Municípios), na garantia da proteção integral e prioritária e na formulação e fiscalização das políticas sociais, com destaque para os Conselhos de Direitos da Criança e do Adolescente.

Nessa linha de entendimento Melim (2012) pontua que desde a promulgação deste marco regulatório no Brasil há uma infinidade de esforços de atores sociais ligados à área governamental e a sociedade civil, como por exemplo, os profissionais que atuam com demandas que envolvem crianças e adolescentes e ativistas da luta pela defesa da cidadania e emancipação desses sujeitos, que vêm sendo desenvolvidos.

As inovações nesses anos de existência do ECA podem ser observadas nas proposições de Planos Nacionais, Estaduais e Municipais de programas em diversas frentes de trabalho como é o caso dos que envolvem direitos ameaçados e/ou violados.

As políticas de atendimento ofertadas pela Assistência Social às crianças e aos adolescentes em situação de violência doméstica, objeto das análises deste artigo, apresentam evoluções importantes no que tange a proteção social.

A instituição de CRAS em mais de 5.000 municípios brasileiros (BRASIL, 2004; 2013); a criação de CREAS, o que inclui as modalidades municipais e regionais em diversos cantos do país; a ampliação das normativas e legislações que balizam o SUAS; o desenvolvimento de programas, projetos, serviços e benefícios para as famílias em situação de vulnerabilidade e risco social e pessoal por violações de direitos; o trabalho multidisciplinar e em rede; as construções de olhares para a centralidade da família e o respeito às diversidades identificadas, são alguns exemplos dos avanços obtidos nos últimos anos na área da Assistência Social.

Juntam-se aos avanços elencados a implementação dos canais de denúncia com ênfase para o Disque 100; a realização de campanhas educativas como o "Faça Bonito", realizada no dia 18 de maio em virtude do Dia Nacional de Combate ao Abuso e à Exploração de Crianças e Adolescentes; o fortalecimento e a expansão dos Conselhos Tutelares; a organização do Sistema de 
Garantia de Direitos (Resolução nำ 116 do CONANDA); a aprovação da "Lei da Palmada" (BRASIL, 2014); entre outros.

No entanto, o cenário atual é marcado pelas imposições neoliberais que empregam um encolhimento das ações interventivas do Estado, principalmente nas políticas sociais, sobretudo no âmbito da proteção social, o que ocasiona a precarização das unidades responsáveis pela oferta das políticas de atendimento. Os cortes, a limitação de recursos financeiros, humanos e materiais, a retração de direitos sociais duramente conquistados, são expressões reais da ofensiva neoliberal. Essa lógica destrutiva gera rebatimentos diretos no processo de consolidação do ECA no Brasil.

O Estado neoliberal retrai os seus investimentos na universalização dos serviços sociais públicos e impulsiona políticas sociais cada vez mais focalizadas, o que faz com que a proteção social seja mais direcionada para as crianças e adolescentes pobres, resgatando as velhas práticas da trajetória de atenção a infância e adolescência no país. $O$ atendimento apenas de uma parcela da população compromete as perspectivas de cidadania e direitos sociais, reforça os traços assistencialistas e embala a esfera do mercado (MELIM, 2012).

A partir destas considerações é possível frisar que a Doutrina da Proteção Integral tem a sua efetivação fragilizada em meio às orientações neoliberais, pois apesar de o ECA garantir direitos e políticas de atendimento para todas as crianças e adolescentes, a sociedade é dividida em classes, o que corrobora para que o acesso a tais direitos muitas das vezes seja diferenciado, especificidades da sociedade capitalista. Acrescentam-se ainda os traços culturais de reprodução da perspectiva do "menor" que ainda se fazem presentes.

A vivência por muitas crianças e adolescentes de situações de violência doméstica (física, psicológica, negligência, abandono, maus tratos e sexual - abuso e/ou exploração), assim como outras formas (como o trabalho infantil) demarca que os seus direitos permanecem sendo violados nos contextos sociofamiliares. Isso significa dizer que a atenção à infância e à adolescência ainda revela muitas lacunas que precisam ser preenchidas.

O desmonte das políticas sociais, o que inclui a Assistência Social; o deficit público; a criminalização dos movimentos sociais; a fragilização dos espaços de controle social, como os Conselhos de direitos e as Conferências; a escassez de políticas e estratégias do Governo Federal para o enfrentamento das violências considerando as discrepâncias regionais; o reforço de pressupostos conservadores e culturais que suavizam as situações de violência vividas pelas crianças e adolescentes; a falta de mobilizações e de mais campanhas educativas diante dos dados crescentes de violências; a insuficiência de profissionais nas unidades de atendimento; são exemplos dos limites que entravam a concretização do ECA em uma perspectiva de totalidade no momento atual.

Nos trinta anos do ECA as projeções estatísticas evidenciam um crescimento alarmante de ocorrências de situações de violência que envolvem crianças e adolescentes, principalmente diante do cenário de pandemia da Covid-192. Os dados revelam a necessidade de medidas incisivas de defesa, proteção e responsabilização por parte da tríade Família/Estado/Sociedade para que assim, mesmo diante das intempéries desse processo desumanizador do neoliberalismo os impactos sobre a infância e adolescência sejam enfrentados e minimizados.

\footnotetext{
${ }^{2}$ A COVID-19 é uma doença causada pelo coronavírus SARS-CoV-2 e ocasiona um quadro clínico marcado por infecções respiratórias leves, moderadas e graves. A Organização Mundial de Saúde (OMS) em março de 2020 decretou estado de pandemia devido o surto da doença em diversos países do mundo (BRASIL, 2020).
} 


\section{Considerações Finais}

As discussões aqui expostas a partir de uma análise documental e bibliográfica evidenciam que o ECA representa um marco regulatório inovador no que se refere às concepções e práticas de atenção a infância e adolescência no Brasil. Isso significa dizer que no decorrer desses trinta anos desde a sua aprovação muitos esforços têm sido empreendidos na tentativa de garantir a sua aplicabilidade às crianças e aos adolescentes brasileiros.

É diante dessa compreensão que vale ressaltar as conquistas normativas implementadas nesse lastro de tempo na direção de garantia de direitos e proteção social, o que abrange as estratégias preventivas e de enfrentamento das manifestações de violência doméstica contra crianças e adolescentes. Todavia, as imposições capitalistas no cenário contemporâneo adquirem conotações aguçadas e geram o acirramento das expressões da questão social. Dessa forma, o processo de consolidação do ECA e a operacionalização das políticas sociais são marcadas pelas vicissitudes dessa sociabilidade.

O caminho construído pela Assistência Social permite considerar o marco transitório de ações descontinuadas e isoladas para propostas embasadas teoricamente em um novo patamar de proteção social, tendo como referência a CF (1998) e as demais normativas que testificam o SUAS. Consequentemente as políticas de atendimento previstas no art. 87 do ECA direcionadas à prevenção e redução de violações de direitos assim como ao atendimento especializado às vítimas, puderam ser operacionalizadas nos CRAS, CREAS e Instituições de Acolhimento por meio dos seus serviços e programas.

Entretanto, algumas questões comprometem a efetividade das políticas de atendimento supracitadas. A ausência de serviços exclusivos para atendimento das situações de violência doméstica, uma vez que nos serviços tipificados, como é o caso do PAEFI, as equipes técnicas precisam atender outras demandas afins da Assistência Social de modo concomitante; a otimização e escassez de recursos humanos, materiais e financeiros nas unidades desta política; as dificuldades dos Conselhos Tutelares no desenvolvimento de suas ações enquanto órgão protetivo; os impasses na relação e diálogo do SUAS com o Sistema de Justiça no que tange as atribuições dos profissionais deste sistema; o baixo número de CREAS no país e a pouca divulgação dos seus serviços; os traços estruturais e culturais de interpretação das violências; e a insuficiência em alguns momentos da adesão das famílias às propostas interventivas são exemplos dos entraves e desafios enfrentados.

Somam-se a isto, as fragilidades e fissuras das articulações entre a Assistência Social e as redes de Saúde, Educação e Direitos Humanos em prol da proteção a ameaça ou violação de direitos das crianças e adolescentes, que externam uma desarticulação entre os atores profissionais, necessitando-se a construção de uma agenda comum que inclua capacitações continuadas, protocolos de atendimento, fluxos, com o intuito de que a intersetorialidade possibilite novos ganhos para a atenção à infância e à adolescência.

O enfrentamento da violência doméstica requer reflexões contínuas sobre questões importantes para se viabilizar a desconstrução das relações de gênero machistas e patriarcais imbuídas na nossa atual sociedade, maior compreensão sobre a infância e a adolescência, ampliação da educação em direitos humanos, ressignificação do papel dos pais e responsáveis e suas formas de educar. Faz-se necessário ainda a promoção de diferentes modos de comunicação não violentos, como alternativa aos conflitos intrafamiliares, diminuindo-se as chances de práticas agressivas e opressoras. 
Destarte, as políticas de atendimento da Assistência Social para as crianças e adolescentes em situação de violência doméstica ainda se encontram em fase de construção, o que demonstra a pertinência histórica dos governos, das instituições, dos profissionais que trabalham com este público e dos defensores de direitos humanos de se comprometerem com a construção de novas mediações de prevenção, enfrentamento e superação de tais violações, sem perder de vista as responsabilidades da Família, do Estado e da Sociedade na garantia da proteção integral, até porque como dizia Bertolt Brecht, “[...] As revoluções se produzem nos becos sem saída”.

\section{Referências}

ARIÈS, Philippe. História social da criança e da família. Rio de Janeiro: Zahar; 2a ed. 1981.

BRASIL. Constituição da República Federativa do Brasil. Brasília: 1988. Disponível em: http://www.planalto.gov.br/ccivil_03/constituicao/constituicao.htm. Acesso: 15 jun. 2020.

BRASIL. Presidência da República. Estatuto da Criança e do Adolescente: Lei no 8.069, de 13 de julho de 1990. Brasília: 1990. Disponível em: http://www.planalto.gov.br/ccivil_03/leis/l8069.htm. Acesso: 15 jun. 2020.

BRASIL. Presidência da República. Lei federal n8.742, de 7 de dezembro de 1993. Dispõe sobre a organização da Assistência Social e dá outras providências. Brasília, DF, 1993. Disponível em: http:// www.planalto.gov.br/ccivil_03/leis/l8742.htm. Acesso em 30 jun. 2020.

BRASIL. Presidência da República. Lei federal no 13.010, de 26 de junho de 2014. Altera a Lei no 8.069, de 13 de julho de 1990 (Estatuto da Criança e do Adolescente), para estabelecer o direito da criança e do adolescente de serem educados e cuidados sem o uso de castigos físicos ou de tratamento cruel ou degradante, e altera a Lei no 9.394, de 20 de dezembro de 1996. Disponível em: http://www.planalto. gov.br/ccivil_03/_ato2011-2014/2014/lei/l13010.htm. Acesso em: 18 jul. 2020.

BRASIL. Ministério da Saúde. O que é COVID-19? Brasília, 2020. Disponível em: https://coronavirus. saude.gov.br/sobre-a-doenca. Acesso em: 09 nov. 2020.

BRASIL. Ministério da Família, da Mulher e dos Direitos Humanos. Relatório de denúncias de violações de direitos de criança e adolescentes em 2019. Disque Direitos Humanos.Brasília, DF: MFMDH, 2019. Disponível em: https://www.gov.br/mdh/pt-br/acesso-a-informacao/ouvidoria/ Disque100Relatorio_Crianaeadolescentes.pdf. Acesso em 15 jul. 2020.

BRASIL. Ministério da Justiça. Secretaria de Estado dos Direitos Humanos. Plano Nacional de Enfrentamento da Violência Sexual contra Crianças e Adolescentes. Brasília, DF: MDH, 2002. Disponível em: http://www.movimentodeemaus.org/data/material/plano-nacional-deenfrentamento-a-violencia-sexual-contra-criancas-e-adolescentes.pdf. Acesso em 04 jul. 2020.

BRASIL. Ministério da Previdência e Assistência Social. Secretaria de Estado de Assistência Social. Portaria no 878, de 03 de dezembro de 2001. Estabelece diretrizes e normas do Programa Sentinela e dá outras providências. Brasília, DF, 2001. Disponível em: http://www.mds.gov.br/webarquivos/ legislacao/assistencia_social/portarias/2001/Portaria\%20no\%20878-\%20de\%2003\%20de\%20 dezembro\%20de\%202001.pdf. Acesso em 04 jul. 2020.

BRASIL. Ministério do Desenvolvimento Social. Secretaria de Avaliação e Gestão da Informação; Secretaria Nacional de Assistência Social. Curso de Atualização sobre a organização e oferta dos serviços da proteção social especial. Brasília, DF: MDS, 2017. 
BRASIL. Ministério do Desenvolvimento Social e Combate à Fome. Secretaria Nacional de Assistência Social. Censo Suas 2011: CRAS, CREAS, Centros POP, Gestão Municipal, Gestão Estadual, Conselhos Municipais, Conselhos Estaduais e Rede Privada. Brasília, DF: MDS, 2013.

BRASIL. Ministério do Desenvolvimento Social e Combate à Fome. Plano Nacional de Promoção, Proteção, Defesa do Direito de Crianças e Adolescentes à Convivência Familiar e Comunitária. Brasília, DF: MDS, 2006.

BRASIL. Ministério do Desenvolvimento Social e Combate à Fome. Secretaria Nacional de Assistência Social. Política Nacional de Assistência Social. Brasília, DF: MDS, 2004.

BRASIL. Ministério do Desenvolvimento Social e Combate à Fome. Secretaria Nacional de Assistência Social. Tipificação Nacional de Serviços Socioassistenciais. Brasília, DF: MDS, 2009.

CHAUÍ, Marilena. Ensaio: Ética e Violência. In: Fundação Perseu Abramo. Teoria \& Debate. outdez/1998. Disponível em: https://teoriaedebate.org.br/1998/10/01/etica-e-violencia/. Acesso em: 04 jul. 2020.

DEL PRIORE, Mary. História da infância no Brasil. 4ª edição. São Paulo: Editora Contexto, 2004.

DOLINGER, Jacob. Criança no Direito Internacional. In: A Família no Direito Internacional Privado Parte 2. Rio de Janeiro: Renovar, 2003.

FALEIROS, Vicente de Paula. Redes de Exploração e Abuso Sexual e Redes de Proteção. Trabalho apresentado no $9^{\circ}$ Congresso Brasileiro de Assistentes Sociais. Goiânia - Julho de 1998, Anais - Vol. 1p.267-271.

IAMAMOTO, Marilda Villela. A questão social no capitalismo. Temporalis: Revista da Associação Brasileira de Ensino e Pesquisa em Serviço Social. Brasília, v. 2, n. 3, p. 9-31, jan-jun/2001.

IAMAMOTO, Marilda Villela. Serviço Social em tempo de fetiche: capital financeiro, trabalho e questão social. 2. ed. São Paulo: Cortez, 2008.

JACCOUD, Luciana. Proteção social no Brasil: debates e desafios. MDS, UNESCO, Nov, 2009, p. 57-86.

KRUG, E. G. et al. (Ed.). Relatório mundial sobre violência e saúde. Genebra: Organização Mundial da Saúde, 2002.

MARTINS, Christine Baccarat de Godoy; JORGE, Maria Helena Prado de Mello. Maus-tratos infantis: um resgate da história e das políticas de proteção. Acta Paulista de Enfermagem, São Paulo, v. 23, n. 3, p. 417-422, jun, 2010. Disponível em: https://www.scielo.br/scielo.php?script=sci_arttext\&pid=S010321002010000300018\&lang=pt. Acesso em: 20 jun. 2020.

MELIM, Juliana Iglesias. Trajetória da proteção social brasileira à infância e a adolescência nos marcos das relações sociais capitalistas. Serv. Soc.\& Saúde, Campinas, SP v. 11, n. 2 (14) p. 167184 Jul./Dez. 2012. Disponível em: https://periodicos.sbu.unicamp.br/ojs/index.php/sss/article/ view/8635161. Acesso em 15 jun. 2020.

MINAYO, Maria Cecília de Souza. A violência dramatiza suas causas. In: MINAYO, Maria. Celília; SOUZA, Edinilsa. Ramos de. (Orgs). Violência sob o olhar da saúde: a infrapolítica da contemporaneidade brasileira. Rio de Janeiro: Fiocruz, 2003.

MINAYO, Maria Cecília de Souza. Violência contra crianças e adolescentes: questão social, questão de saúde. Rev. Bras. Saúde Mater. Infant. Recife, v.1, n.2; p.91-102, mai-ago, 2001. Disponível em: https://www.scielo.br/scielo.php?pid=S1519-38292001000200002\&script=sci_abstract\&tlng=pt. Acesso em: 15 jul. 2020. 
MINAYO, Maria Cecília de Souza. Conceitos, teorias e topologias de violência: a violência faz mal à saúde. In: NJAINE, Kathie; ASSIS, Simone Gonçalves; CONSTANTINO, Patrícia (Orgs.). Impactos da Violência na Saúde. Rio de Janeiro: EAD/ENSP, p.21-42, 2013.

NASCIMENTO, Alexandre Ferreira do; DESLANDES, Suely Ferreira. A construção da agenda pública brasileira de enfrentamento da violência sexual infanto-juvenil. Physis, Rio de Janeiro, v. 26, n. 4, p. 1171-1191, Out. 2016. Disponível em: https://www.scielo.br/scielo.php?script=sci_arttext\&pid =S0103-73312016000401171. Acesso em: 04 jul. 2020.

RIZZINI, Irene. 0 século perdido: raízes históricas das políticas públicas para a infância no Brasil. Rio de Janeiro: Santa Úrsula, 1997.

RIZZINI, Irene; NAIFF, Luciene BAPTISTA, Rachel. (Coord.). Acolhendo crianças e adolescentes: experiências de promoção do direito à convivência familiar e comunitária no Brasil. São Paulo: Cortez; Brasília: Unicef; Rio de Janeiro: PUC-Rio, 2006. 